\title{
Effect of Dietary L-arabinose on the Intestinal Microbiota and Metabolism of Dietary Daidzein in Adult Mice
}

\author{
Motoi TAMURA $^{1 *}$, Yukie KURUSU1 and Sachiko Hori ${ }^{1}$ \\ ${ }^{1}$ National Food Research Institute, National Agriculture and Food Research Organization, 2-1-12 Kannondai, Tsukuba, Ibaraki \\ 305-8642, Japan
}

Received December 8, 2011; Accepted February 10, 2012

\begin{abstract}
This study examined the effects of L-arabinose on mouse intestinal microbiota and urinary isoflavonoids. Male mice were randomly divided into two groups: those fed a $0.05 \%$ daidzein-2.5\% L-arabinose diet (AR group) and those fed a $0.05 \%$ daidzein control diet (CO group) for 28 days. The amounts of daidzein detected in urine were significantly lower in the AR group than in the CO group. The ratio of equol/daidzein was significantly higher in the AR group $(\mathbf{p}<\mathbf{0 . 0 1})$ than in the CO group. The composition of caecal flora differed between the AR and CO groups. The occupation ratios of Prevotella and Lactobacillales were significantly lower in the AR group. This study suggests that dietary L-arabinose has the potential to affect the metabolism of equol from daidzein by altering the metabolic activity of intestinal microbiota.
\end{abstract}

Key words: L-arabinose; equol; daidzein; mice; intestinal microbiota

Much attention has recently focused on the health benefits of soy-based foods. These health benefits have been largely attributed to isoflavones. Daidzin, genistin, daidzein (the aglycone of daidzin) and genistein (the aglycone of genistin) are the most common isoflavones found in soy products. Isoflavones are a class of phytooestrogens. Phyto-oestrogens are defined as compounds that exert estrogenic effects on the central nervous system, induce estrus and stimulate growth of the genital tract in female animals [1]. Human gastrointestinal bacteria seem to play an important role in isoflavone metabolism [2, 3]. Equol is a metabolite of daidzein and is produced by intestinal flora [4]. Equol is more effective than daidzein in competing with ${ }^{3} \mathrm{H}$-oestradiol to bind to the estrogen receptor, suggesting that it has a higher affinity for this receptor [5]. It has also been suggested that the ability to produce equol or equol itself is closely related to a lower incidence of prostate cancer [6]. Thus, equol is an important bacterial metabolite in the gut. However, interindividual variations in equol production have been identified. Only $30 \%$ to $50 \%$ of humans are equol producers [7]. It has been reported that the frequency of equol producers among vegetarians is

*Corresponding author. Mailing address: Motoi Tamura, National Food Research Institute, National Agriculture and Food Research Organization, 2-1-12 Kannondai, Tsukuba, Ibaraki 305-8642, Japan. Phone: +81-298-38-8089. Fax: +81-298-38-7996. E-mail motoita@affrc.go.jp
$59 \%$, similar to the reported frequency in Japanese adults consuming soy and much higher than that among nonvegetarian adults $(25 \%)$, suggesting that dietary components other than soy influence S-equol synthesis by intestinal bacteria [8]. Rowland et al. [9] demonstrated that humans who excrete high concentrations of equol consume less fat and more carbohydrates as a percentage of energy than humans who excrete low concentrations of equol. The bioavailability of isoflavonoids seems to be affected by the composition of the diet. L-Arabinose, a natural, sweet and less absorptive pentose, has been recognized to have a selective inhibitory effect on intestinal sucrase activity in rats [10] and humans [11]. It has been reported that $4 \%$ L-arabinose in sucrose beverages reduces postprandial glucose, insulin and C-peptide responses and enhances the glucagon-like peptide- 1 response in humans without gastrointestinal adverse effects [11]. Plasma insulin and triacylglycerol concentrations were significantly reduced by dietary arabinose in rats [12]. LArabinose ingestion with sucrose appears to effectively increase the production of organic acids in the caecum of the rat [13]. L-Arabinose affects gut function and intestinal microbiota $[11,13]$.

On the other hand, intestinal microbiota seem to play an important role in isoflavone metabolism [2, 4]. We tested the hypothesis that dietary L-arabinose changes the metabolism of daidzein and intestinal microbiota in 
mice. The aim of the present study was to investigate these effects in mice. Daidzein and equol were purchased from LC Laboratories (Woburn, MA, USA). $\beta$ Glucuronidase type H-5 was obtained from Sigma (St. Louis, MO, USA). Male Crj:CD-1 mice (6 weeks old) were purchased from Charles River Laboratories Japan, Inc. (Kanagawa, Japan). All mice were specific pathogen-free and were housed under conventional conditions in our laboratory. The mice were randomly divided into two groups of seven animals each. The animals were housed individually in suspended stainless steel cages with wire mesh bottoms in a room kept at $24 \pm 0.5^{\circ} \mathrm{C}$ and a relative humidity of $65 \%$, with $12-\mathrm{hr}$ periods of light and dark. They were fed an AIN-93M diet for $7 \mathrm{~d}$. After $7 \mathrm{~d}$, the diet was replaced with a $0.05 \%$ daidzein control diet (CO diet) or a $0.05 \%$ daidzein$2.5 \% \mathrm{~L}$-arabinose diet (AR diet), and the mice received the CO or AR diet for $28 \mathrm{~d}$. Twenty-one days after beginning to feed the experimental diet, all animals were moved to metabolic cages (Tecniplast S.p.a., Buguggiate (Va), Italy). The animals were housed individually in these metabolic cages. Urine was collected from all mice. Urinary amounts of isoflavonoids were measured. The purified diet and water were provided ad libitum. The CO diet (control diet) contained $0.5 \mathrm{~g} / \mathrm{kg}$ daidzein, $465.192 \mathrm{~g} / \mathrm{kg}$ corn starch, $140 \mathrm{~g} / \mathrm{kg}$ casein, $154.5 \mathrm{~g} / \mathrm{kg} \alpha-$ cornstarch, $100 \mathrm{~g} / \mathrm{kg}$ sucrose, $40.0 \mathrm{~g} / \mathrm{kg}$ soybean oil, 50.0 $\mathrm{g} / \mathrm{kg}$ cellulose, $35.0 \mathrm{~g} / \mathrm{kg}$ mineral mix (AIN-93M-Mix), (AIN-93-Mix) $10 \mathrm{~g} / \mathrm{kg}$ vitamin mix, $1.8 \mathrm{~g} / \mathrm{kg}$ L-cystine, $2.5 \mathrm{~g} / \mathrm{kg}$ choline bitartrate, $0.008 \mathrm{~g} / \mathrm{kg}$ tertbutylhydroquinone. The AR diet contained, $0.5 \mathrm{~g} / \mathrm{kg}$ daidzein, $465.192 \mathrm{~g} / \mathrm{kg}$ corn starch, $140 \mathrm{~g} / \mathrm{kg}$ casein, $154.5 \mathrm{~g} / \mathrm{kg} \alpha$-cornstarch, $100 \mathrm{~g} / \mathrm{kg}$ sucrose, $40.0 \mathrm{~g} / \mathrm{kg}$ soybean oil, $25.0 \mathrm{~g} / \mathrm{kg}$ cellulose, $25.0 \mathrm{~g} / \mathrm{kg}$ L-arabinose, $35.0 \mathrm{~g} / \mathrm{kg}$ mineral mix (AIN-93M-Mix), $10 \mathrm{~g} / \mathrm{kg}$ vitamin mix (AIN-93-Mix), $1.8 \mathrm{~g} / \mathrm{kg}$ L-cystine, $2.5 \mathrm{~g} / \mathrm{kg}$ choline bitartrate, $0.008 \mathrm{~g} / \mathrm{kg}$ tert-butylhydroquinone. Body weight and food consumption were measured, and faeces were collected during the experiment. Faeces were dried with a freeze dryer (FD-1000; Tokyo Rikakikai Co., Ltd., Tokyo, Japan) for $24 \mathrm{hr}$. The trap cooling temperature was $-45^{\circ} \mathrm{C}$. Weights of freeze-dried faeces were measured during the experiment. After the experimental diet-feeding period, the mice were anaesthetized with diethyl ether, and blood samples were taken from the abdominal aorta and placed in heparinized tubes. All mice were euthanized with diethyl ether. The plasma was separated from whole blood by centrifugation and stored at $-80^{\circ} \mathrm{C}$ until analysis of plasma glucose. The liver, visceral fat and caecal contents were collected. Caecal contents were stored at - $80^{\circ} \mathrm{C}$ until HPLC analysis for later terminal restriction fragment length polymorphism (T-RFLP) analysis of intestinal microbiota. The liver samples and visceral fat were weighed.

All procedures involving mice in this study were approved by the Animal Care Committee of the National Food Research Institute in Japan and were performed in accordance with the "Guidelines for Animal Care and Experimentation' of the National Food Research Institute of the National Agriculture and Food Research Organization in Japan. A total of $200 \mu 1$ of urine was added to $200 \mu \mathrm{l}$ of $\beta$-glucuronidase $\mathrm{H}-5$ solution $(35 \mathrm{mg} /$ $\mathrm{ml}$; Sigma, St. Louis, MO, USA) in $0.2 \mathrm{M}$ sodium acetate buffer (pH 5.0). Next, the mixture was incubated at $37^{\circ} \mathrm{C}$ in a water bath for $3 \mathrm{hr}$, followed by treatment with $400 \mu \mathrm{l}$ of ethyl acetate, vortexing for $30 \mathrm{sec}$, and centrifugation at $5,000 \mathrm{~g}$ for $10 \mathrm{~min}$ at $4{ }^{\circ} \mathrm{C}$. The supernatants were transferred to an eggplant-type flask. The same volume of ethyl acetate as that used in the first extraction was added to the sediment, and the procedure was repeated. The supernatants from both extractions were pooled in the eggplant-type flask and evaporated completely using a rotary evaporator. The sample was then dissolved in $400 \mu$ of $80 \%$ methanol and filtrated through a $0.2-\mu \mathrm{m}$ filter. Filtrates were used for HPLC analysis. For HPLC analysis, we injected $20 \mu \mathrm{l}$ of each preparation into a 250x4.6-mm Capcell Pak MG C18 5$\mu \mathrm{m}$ column (Shiseido, Tokyo, Japan). To detect isoflavonoids, a photodiode array detector (MD-1515; JASCO, Corporation, Tokyo, Japan) was used to monitor the spectral data from 200 to $400 \mathrm{~nm}$ for each peak. To measure the isoflavonoids, we used daidzein and equol as standard samples. We used the spectral data at $254 \mathrm{~nm}$ to quantify daidzein and the spectral data at $280 \mathrm{~nm}$ to quantify equol. The mobile phase consisted of methanol/ acetic acid/water $(35: 5: 60, \mathrm{~V} / \mathrm{V} / \mathrm{V})$. The running conditions of HPLC were a column temperature of $40^{\circ} \mathrm{C}$ and a flow rate of $1 \mathrm{ml} / \mathrm{min}$. DNA extractions from caecal contents were conducted according to Matsuki's method [14]. Caecal samples (20 mg) were washed three times by suspending them in $1.0 \mathrm{ml}$ of phosphatebuffered saline and centrifuging each preparation at $14,000 \mathrm{~g}$ to remove possible PCR inhibitors. Following the third centrifugation, the caecal pellets were resuspended in a solution containing $0.2 \mathrm{ml}$ of phosphate-buffered saline and $250 \mu \mathrm{l}$ of extraction buffer (200 mM Tris-HCl, $80 \mathrm{mM}$ EDTA; $\mathrm{pH} 9.0$ ) and $50 \mu \mathrm{l}$ of $10 \%$ sodium dodecyl sulfate. A total of $300 \mathrm{mg}$ of glass beads (diameter, $0.1 \mathrm{~mm}$ ) and $500 \mu \mathrm{l}$ of buffer-saturated phenol were added to the suspension, and the mixture was vortexed vigorously for $60 \mathrm{sec}$ using a Mini- 
BeadBeater (BioSpec Products Inc., Bartlesville, OK, USA) at $4800 \mathrm{rpm}$. Following centrifugation at $14,000 \mathrm{~g}$ for $5 \mathrm{~min}, 400 \mu \mathrm{l}$ of the supernatant was collected. Phenol-chloroform-isoamyl alcohol extractions were then performed, and $250 \mu \mathrm{l}$ of the supernatant was subjected to isopropanol precipitation. Finally, the DNA was suspended in $1 \mathrm{ml}$ of Tris-EDTA buffer. The DNA preparation was adjusted to a final concentration of 10 $\mu \mathrm{g} / \mathrm{ml}$ in TE and checked by $1.5 \%$ agarose gel electrophoresis.

The PCR mixture $(25 \mu \mathrm{l})$ was composed of EX Taq buffer, $2 \mathrm{mM}$ of $\mathrm{Mg}^{2+}$, and each deoxynucleoside triphosphate at a concentration of $200 \mu \mathrm{M}$. The amount of caecal DNA was $10 \mathrm{ng}$. The primers used were $5^{\prime}$ FAM-labelled 516f (5'-TGCCAGCAGCCGCGGTA-3') and $1510 \mathrm{r}\left(5^{\prime}\right.$-GGTTACCTTGTTACGACTT-3') at a concentration of $0.10 \mu \mathrm{M}$, template DNA and $0.625 \mathrm{U}$ of DNA polymerase (TaKaRa EX Taq, Takara Bio Inc., Otsu, Japan). This process was carried out using a Dice PCR system (Takara Bio Inc.). Amplification was performed with one cycle at $95^{\circ} \mathrm{C}$ for $15 \mathrm{~min}$; thirty cycles at $95^{\circ} \mathrm{C}$ for $30 \mathrm{sec}, 50^{\circ} \mathrm{C}$ for $30 \mathrm{sec}$ and $72^{\circ} \mathrm{C}$ for 1 min; and finally one cycle at $72^{\circ} \mathrm{C}$ for $10 \mathrm{~min}$. The amplification products were subjected to gel electrophoresis in $1.5 \%$ agarose followed by ethidium bromide staining. The PCR products were purified using spin columns (QIAquick, Qiagen KK, Tokyo, Japan) according to the manufacturer's instructions. The purified DNA was treated with $2 \mathrm{U}$ of Bsl $I$ (New England Biolabs) for $3 \mathrm{hr}$ at $55^{\circ} \mathrm{C}[15]$.

T-RFLP (terminal restriction fragment length polymorphism) analysis is based on PCR amplification of a target gene. The amplification is performed with one primer whose $5^{\prime}$ end is labelled with a fluorescent molecule. The mixture of amplicons is then subjected to a restriction reaction using a restriction enzyme. Following the restriction reaction, the mixture of fragments is separated using either capillary or polyacrylamide electrophoresis in a DNA sequencer, and the sizes of the different terminal fragments are determined by the fluorescence detector. We used this TRFLP analysis in our experiment. The fluorescently labelled terminal restriction fragments (T-RFs) were analyzed by electrophoresis on an automated sequence analyzer (ABI PRISM 310 Genetic Analyzer, Applied Biosystems) in GeneScan mode. The restriction enzyme digestion mixture $(2 \mu \mathrm{l})$ was mixed with $0.5 \mu \mathrm{l}$ of size standards (MapMarker 1000, BioVentures, Inc.) and 12 $\mu \mathrm{l}$ of deionized formamide. The mixture was denatured at $96^{\circ} \mathrm{C}$ for $2 \mathrm{~min}$ and immediately chilled on ice. The injection time was $30 \mathrm{sec}$ for analysis of T-RFs from digestion with BslI. The run time was $40 \mathrm{~min}$. The lengths and peak areas of T-RFs were determined with the GeneMapper software. The predominant operational taxonomic units (OTUs), which correspond to either TRFs or T-RF clusters, were detected in the T-RFLP profiles and used to identify phylogenetic groups of intestinal flora $[15,16]$.

Plasma glucose concentrations were measured using a glucose C2-test kit (Wako Pure Chemical Industries, Osaka, Japan) based on the mutarotase glucose oxidase method.

All faeces were collected during the experiment. Weights of faeces were measured. Faeces were then dried with a freeze dryer (FD-1000, Tokyo Rikakikai Co., Ltd., Tokyo, Japan) for $24 \mathrm{hr}$. The trap cooling temperature was $45^{\circ} \mathrm{C}$. After drying, the weights of freeze-dried faeces were measured. Faecal lipid contents (\%) were determined from the faeces sampled on the final days of the experiment. Faeces were milled with a food mill (TML17; TESCOM \& Co., Ltd., Tokyo, Japan) for $30 \mathrm{sec}$. Faecal lipids were extracted from the faecal powder by Bligh and Dyer's method [17]. Data are expressed as the mean \pm standard error (SE). All data were analyzed using Sigma Plot 11 (Systat Software, Inc., San Jose, CA, USA). The data were analyzed with the t-test. Statistical significance was reached with a $\mathrm{p}$ value of $<0.05$.

\section{RESULTS AND DISCUSSION}

No significant differences were observed between the $\mathrm{AR}$ and $\mathrm{CO}$ groups in final body weight ( $\mathrm{g}$ ) (AR, $33.3 \pm 0.6$; $\mathrm{CO}, 32.7 \pm 0.6$ ), food consumption (g/d) (AR, $4.15 \pm 0.05 ; \mathrm{CO}, 4.23 \pm 0.04)$, visceral fat $(\mathrm{g})(\mathrm{AR}$, $1.29 \pm 0.30 ; C O, 1.34 \pm 0.42$ ), faecal contents (AR, $0.20 \pm 0.05 ; \mathrm{CO}, 0.18 \pm 0.04)$ or liver weight ( $\mathrm{g})(\mathrm{AR}$, $1.35 \pm 0.05$; $\mathrm{CO}, 1.40 \pm 0.03$ ).

The urinary amounts of daidzein were significantly higher in the CO group than in the AR group $(p<0.05)$ (Fig. 1A). Average urinary amounts of equol tended to be higher in the AR group than in the CO group. However, no significant differences were observed between the urinary amounts of equol in the AR and CO groups. The ratio of equol/daidzein was significantly higher in the AR group $(\mathrm{p}<0.01)$ than in the CO group (Fig. 1B). No significant differences in the amounts of urine $(\mathrm{ml})$ collected for $45 \mathrm{hr}$ were observed between the AR $(1.8 \pm 0.6)$ and $\mathrm{CO}(1.2 \pm 0.3)$ groups. No significant differences in plasma glucose (mg/dl) (AR, 292.8 \pm 11.5 ; $\mathrm{CO}, 269.6 \pm 99.2)$ were observed between the AR and CO groups. The AR diet significantly affected both the amount of faeces and the faecal lipid content. The 


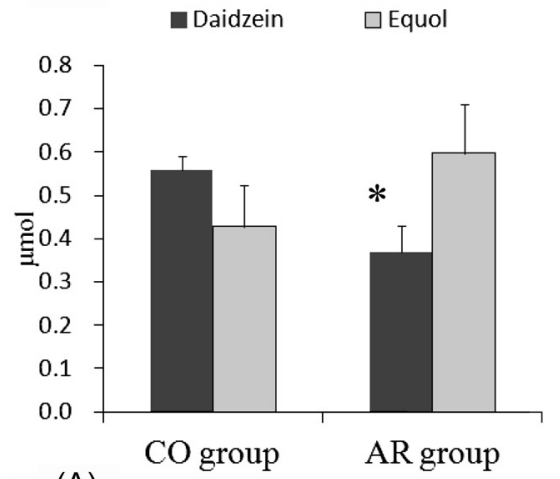

(A)

$$
\text { CO group AR group }
$$

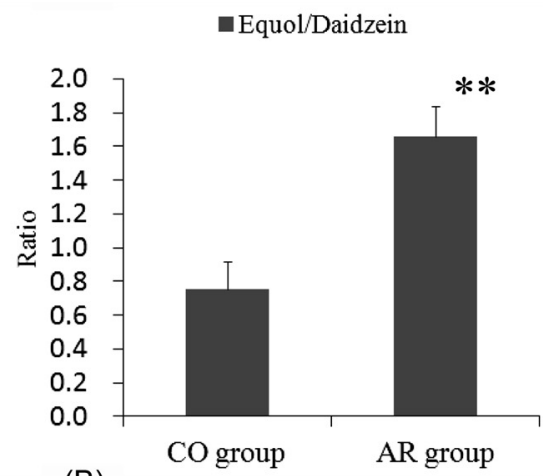

(B)

Fig. 1. (A) Amounts of urinary isoflavonoids (aglycones+metabolites) of mice in the AR group and the $\mathrm{CO}$ group. Values are means $\pm \mathrm{SE}(\mathrm{n}=7)$. ${ }^{*}$ Significantly different $(\mathrm{p}<0.05)$ from the $\mathrm{CO}$ group. (B) The ratio of equol/daidzein from the amounts of urinary isoflavonoids (aglycones+metabolites) of mice in the AR group and the $\mathrm{CO}$ group. Values are means $\pm \operatorname{SE}(n=7)$. *Significantly different $(\mathrm{p}<0.05)$ from the CO group. The data were analyzed using $t$-test analysis. Statistical significance was reached with a $\mathrm{p}$ value of less than 0.05 .

amount of faeces was significantly greater in the $\mathrm{CO}$ group $(0.34 \pm 0.003)$ than in the AR group $(0.25 \pm 0.002)$ $(p<0.01)$. The faecal lipid contents $(\% \mathrm{DW})$ of the faeces sampled on the final days of the experiment were significantly greater in the AR group (6.4 \pm 0.3$)$ than in the CO group (4.1 \pm 0.4$)(\mathrm{p}<0.01)$. It has been confirmed that human intestinal microbiota predominantly consist of members of approximately ten phylogenetic bacterial groups and that these bacterial groups can be distinguished by the T-RFLP system developed by Nagashima et al. $[15,16]$. Figure 2 depicts the compositions of the caecal flora, which differed between the two dietary groups. The occupation ratios of Bacteroides (OTUs 469, 853) were significantly higher in the AR group $(\mathrm{p}<0.01)$. The occupation ratios of Bifidobacterium (OTU 124) tended to be high in the AR group ( $\mathrm{p}=0.068)$. On the other hand, the occupation ratios of Lactobacillales (OTUs 332, 520, 657) and Prevotella (OTUs 137, 317) were significantly higher in the CO group $(\mathrm{p}<0.01)$. Daidzein, a major component of the isoflavones, is metabolized to equol by the intestinal bacterial flora [4]. Conversion of daidzein to equol in the gut is important because of its strong estrogenicity compared with daidzein. However, there is large interindividual variation in the metabolism of isoflavones [18]. Equol was reportedly detected in urine from only $20 \%$ of subjects in a soya group across all ages and in only $5 \%$ of subjects in the control group following a soya challenge [19]. On the other hand, the metabolic activity of daidzein seems to be affected by diet [9].

In our results, the urinary amounts of daidzein were

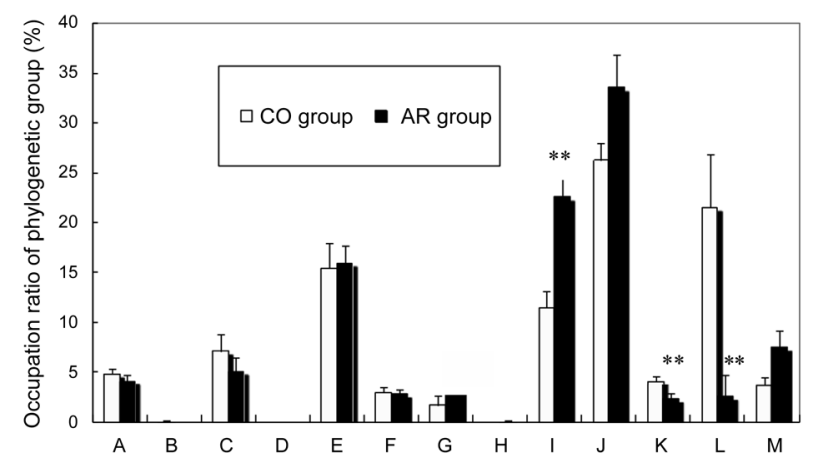

Fig. 2. Composition of caecal intestinal microflora of mice in the AR and $\mathrm{CO}$ groups. OTUs (operational taxonomic units), which correspond to either T-RFs (terminal restriction fragments) or T-RF clusters, were detected by T-RFLP analysis. Values are means $\pm \operatorname{SE}(\mathrm{n}=7)$. **Significantly different $(\mathrm{p}<0.01)$ from the $\mathrm{CO}$ group. The data were analyzed using $\mathrm{t}-$ test analysis. The letters correspond to the following phylogenetic bacterial groups: (A) Bacteroides, Clostridium cluster IV (OTU 370); (B) Clostridium cluster IV (OTUs 168, 749); (C) Clostridium cluster IX, Megamonas (OTU 110); (D) Clostridium cluster XI (OTU 338); (E) Clostridium subcluster XIVa (OTUs 106, 494, 505, 517, 754, 955, 990); (F) Clostridium cluster XI, Clostridium subcluster XIVa (OTU 919); (G) Clostridium subcluster XIVa, Enterobacteriales (OTU 940); H: Clostridium cluster XVIII (OTUs 423, 650); (I) Bacteroides (OTUs 469, 853); (J) Bifidobacterium (OTU124); (K) Lactobacillales (OTUs 332, 520, 657); (L) Prevotella (OTUs 137, 317); (M) Others.

significantly higher in the $\mathrm{CO}$ group than in the AR group. The ratio of equol/daidzein was significantly higher in the AR group $(p<0.01)$ than in the CO group.

Diet composition affects the gut microbial 
composition to a larger extent than previously thought [20], and intestinal microbiota strongly affect isoflavone metabolism in vivo [21]. It has also been reported that subjects with higher PUFA and higher alcohol intake are more likely to be strong equol producers [22]. However, it has also been reported that increased probiotic yogurt or resistant starch intake does not affect isoflavone bioavailability in subjects consuming a high-soy diet [23]. Diet composition may affect equol production from daidzein in the gut by modifying the metabolic activity and/or composition of intestinal microflora. In our results, there were significant differences in the composition of microbiota between the AR and CO groups. It has been reported that butyric acid increases the conversion ratio of daidzein to equol in equolproducing bacteria [24]. Short -chain fatty acids (SCFAs) seem to affect the metabolism of daidzein. It has been reported that Bifidobacterium $[25,26]$ and Bacteroides [27, 28] produce SCFAs. In our experiment, the occupation ratios of Bacteroides and Bifidobacterium were higher in the AR group. Changes in productivity of SCFAs in the gut might be caused by Bacteroides and Bifidobacterium, and these changes might have affected the daidzein-metabolizing bacteria in the faecal flora of the AR group, resulting in the different metabolism between the two dietary groups.

L-Arabinose has been recognized to have a selective inhibitory effect on intestinal sucrase activity and reduces the digestion, absorption and net energy of sucrose when both are simultaneously ingested [10]. Apparent ileal digestibility of L-arabinose was found to be approximately $70 \%$. The presence of L-arabinose in the diet increased ileal flow of volatile fatty acids and lactic acid, suggesting the occurrence of microbial degradation of L-arabinose in the gut of the pig [29]. LArabinose can be used as an energy source for pigs only after microbial fermentation. L-Arabinose feeding increased the production of SCFAs in the caecum of the rat [13]. From these reports, we assume that dietary Larabinose itself may affect the composition and/or metabolic activity of intestinal microbiota by providing sucrose and L-arabinose to the intestinal microbiota in the lower gut. In our results, there were significant differences between the AR and CO groups in the composition of microbiota. Some intestinal bacteria can utilize L-arabinose. It has been reported that the growth of Bifidobacterium longum ATCC 15703 on Larabinose-containing nutrient-poor medium was strong; however, Bifidobacterium breve ATCC 15700 showed no growth on L-arabinose-containing nutrient-poor medium [30]. The different compositions of intestinal microbiota in the two dietary groups might be caused by the difference in availability of L-arabinose of intestinal bacteria. When uniformly ${ }^{14} \mathrm{C}$-labelled sucrose was orally administered at a dose of $2.5 \mathrm{~g} / \mathrm{kg}$ with or without $\mathrm{L}$-arabinose and residual radio activities in the gastrointestinal tract were measured for $6 \mathrm{hr}$, a large quantity of undigested ${ }^{14} \mathrm{C}$-labelled sucrose and its metabolites were observed in the caecum in L-arabinosetreated rats [10]. The different amounts of undigested sucrose in the caecum also contributed to the different compositions of intestinal microbiota in the two dietary groups.

In our results, no significant differences in plasma glucose or visceral fat were observed between the two groups. It has been reported that dietary L-arabinose reduces the blood glucose in rats [13]. The diet in this experiment by Fujii et al. contained $20 \%$ sucrose. On the other hand, our experimental diet contained only $14 \%$ sucrose. These different sucrose contents might have resulted in the different plasma glucose levels.

The AR diet significantly affected both the amount of faeces and faecal lipid content. The amount of faeces was significantly lower in the AR group than in the CO group $(\mathrm{p}<0.01)$. Daily faeces production was reportedly greater in rats fed a diet containing a higher cellulose concentration than in rats fed a diet containing a lower cellulose concentration [31]. Significant increases in faecal weights of rats fed cellulose diets have also been reported [32]. In our experiment, the cellulose content of in the diet was higher in the $\mathrm{CO}$ group than in the AR group. The higher cellulose content in the $\mathrm{CO}$ group may have caused the higher amounts of faeces in the $\mathrm{CO}$ group. The faecal lipid content (\% DW) of the faeces sampled on the final days of the experiment were significantly greater in the AR group than in the $\mathrm{CO}$ group ( $<<0.01)$. These results suggest that the lipid concentration in the lower gut may have been higher in the AR group. It has been reported that dietary fat significantly affects the intestinal microbiota $[33,34]$. Differences in lipid concentrations in the gut might also affect the composition and/or metabolic activities of intestinal microbiota.

The limitation of our study was that we could not identify the bacteria that affect equol production from daidzein. This is the first report concerning the effects of dietary L-arabinose on the metabolism of daidzein in mice. Human studies are needed to clarify the relationship between equol production and metabolism of isoflavones. 


\section{ACKNOWLEDGMENT}

This study was financially supported by grants for project research (Development of fundamental technology for analysis and evaluation of functional agricultural products and functional foods) of the Ministry of Agriculture, Forestry and Fisheries of Japan.

\section{REFERENCES}

1. Lieberman S. 1996. Are the differences between estradiol and other estrogens, naturally occurring or synthetic, merely semantical? J Clin Endocrinol Metab 81: 850-851.

2. Chang YC, Nair MG. 1995. Metabolism of daidzein and genistein by intestinal bacteria. J Nat Prod 58: 1892-1896.

3. Setchell KD, Borriello SP, Hulme P, Kirk DN, Axelson M. 1984. Nonsteroidal estrogens of dietary origin: possible roles in hormone-dependent disease. Am J Clin Nutr 40: 569-578.

4. Bowey E, Adlercreutz H, Rowland I. 2003. Metabolism of isoflavones and lignans by the gut microflora: a study in germ-free and human flora associated rats. Food Chem Toxicol 41: 631-636.

5. Sathyamoorthy N, Wang TT. 1997. Differential effects of dietary phyto-oestrogens daidzein and equol on human breast cancer MCF-7 cells. Eur J Cancer 33: 2384-2389.

6. Akaza H, Miyanaga N, Takashima N, Naito S, Hirao Y, Tsukamoto T, Fujioka T, Mori M, Kim WJ, Song JM, Pantuck AJ. 2004. Comparisons of percent equol producers between prostate cancer patients and controls: case-controlled studies of isoflavones in Japanese, Korean and American residents. Jpn J Clin Oncol 34: 86-89.

7. Devillard E, McIntosh FM, Paillard D, Thomas NA, Shingfield KJ, Wallace RJ. 2009. Differences between human subjects in the composition of the faecal bacterial community and faecal metabolism of linoleic acid. Microbiology 155: 513-520.

8. Setchell KD, Cole SJ. 2006. Method of defining equolproducer status and its frequency among vegetarians. J Nutr 136: 2188-2193.

9. Rowland IR, Wiseman H, Sanders TA, Adlercreutz H, Bowey EA. 2000. Interindividual variation in metabolism of soy isoflavones and lignans: influence of habitual diet on equol production by the gut microflora. Nutr Cancer 36: 27-32.

10. Sanai K, Seri K, Inoue S. 1997. Inhibition of sucrose digestion and absorption by L-arabinose in rats. J Jpn Soc Nutr Food Sci 50: 133-137.

11. Krog-Mikkelsen I, Hels O, Tetens I, Holst JJ, Andersen JR, Bukhave K. 2011. The effects of L-arabinose on intestinal sucrase activity: dose-response studies in vitro and in humans. Am J Clin Nutr 94: 472-478.
12. Osaki S, Kimura T, Sugimoto T, Hizukuri S, Iritani N. 2001. L-arabinose feeding prevents increases due to dietary sucrose in lipogenic enzymes and triacylglycerol levels in rats. J Nutr 131: 796-799.

13. Fujii M, Hatozoe M, Hou De-X, Sanada H, Osaki S, Hizukuri S. 2000. Effects of L-arabinose on serum neutral lipid, weights of fat pads and cecum, and on organic acids in cecum in rats. J Apple Glycosci 47: 355-361.

14. Matsuki T. 2006. Procedure of DNA extraction from fecal sample for the analysis of intestinal microflora. $\mathrm{J}$ Intestinal Microbiol 20: 259-262.

15. Nagashima K, Hisada T, Sato M, Mochizuki J. 2003. Application of new primer-enzyme combinations to terminal restriction fragment length polymorphism profiling of bacterial populations in human feces. Appl Environ Microbiol 69: 1251-1262.

16. Nagashima K, Mochizuki J, Hisada T, Suzuki S, Shimomura K. 2006. Phylogenetic analysis of $16 \mathrm{~S}$ ribosomal RNA gene sequences from human fecal microbiota and improved utility of terminal restriction fragment length polymorphism profiling. Biosci Microflora 25: 99-107.

17. Bligh EG, Dyer WJ. 1959. A rapid method of total lipid extraction and purification. Can J Biochem Physiol 37: 911-917.

18. Rowland I, Faughnan M, Hoey L, Wahala K, Williamson G, Cassidy A. 2003. Bioavailability of phyto-oestrogens. Br J Nutr 89 Suppl 1: S45-S58.

19. Hoey L, Rowland IR, Lloyd AS, Clarke DB, Wiseman H. 2004. Influence of soya-based infant formula consumption on isoflavone and gut microflora metabolite concentrations in urine and on faecal microflora composition and metabolic activity in infants and children. Br J Nutr 91: 607-616.

20. Fleissner CK, Huebel N, Abd El-Bary MM, Loh G, Klaus S, Blaut M. 2010. Absence of intestinal microbiota does not protect mice from diet-induced obesity. Br J Nutr 104: 919-929.

21. Xu X, Harris KS, Wang HJ, Murphy PA, Hendrich S. 1995. Bioavailability of soybean isoflavones depends upon gut microflora in women. J Nutr 125: 2307-2315.

22. Bolca S, Possemiers S, Herregat A, Huybrechts I, Heyerick A, De Vriese S, Verbruggen M, Depypere H, De Keukeleire D, Bracke M, De Henauw S, Verstraete W, Van de Wiele T. 2007. Microbial and dietary factors are associated with the equol producer phenotype in healthy postmenopausal women. J Nutr 137: 2242-2246.

23. Larkin TA, Price WE, Astheimer LB. 2007. Increased probiotic yogurt or resistant starch intake does not affect isoflavone bioavailability in subjects consuming a high soy diet. Nutrition 23: 709-718.

24. Minamida K, Tanaka M, Abe A, Sone T, Tomita F, Hara H, Asano K. 2006. Production of equol from 
daidzein by gram-positive rod-shaped bacterium isolated from rat intestine. J Biosci Bioeng 102: 247250.

25. Van der Meulen R, Makras L, Verbrugghe K, Adriany T, De Vuyst L. 2006. In vitro kinetic analysis of oligofructose consumption by Bacteroides and Bifidobacterium spp. indicates different degradation mechanisms. Appl Environ Microbiol 72: 1006-1012.

26. Zhao J, Cheung PC. 2011. Fermentation of betaglucans derived from different sources by bifidobacteria: evaluation of their bifidogenic effect. J Agric Food Chem 59: 5986-5992.

27. Dongowski G, Lorenz A, Anger H. 2000. Degradation of pectins with different degrees of esterification by Bacteroides thetaiotaomicron isolated from human gut flora. Appl Environ Microbiol 66: 1321-1327.

28. Mayhew JW, Onderdonk AB, Gorbach SL. 1975. Effects of time and growth media on short-chain fatty acid production by Bacteroides fragilis. Appl Microbiol 29: 472-475.

29. Schutte JB, de Jong J, van Weerden EJ, Tamminga S. 1992. Nutritional implications of L-arabinose in pigs. Br J Nutr 68: 195-207.

30. Pastell H, Westermann P, Meyer AS, Tuomainen P,
Tenkanen M. 2009. In vitro fermentation of arabinoxylan-derived carbohydrates by bifidobacteria and mixed fecal microbiota. J Agric Food Chem 57: 8598-8606.

31. Wijnands MV, Appel MJ, Hollanders VM, Woutersen RA. 1999. A comparison of the effects of dietary cellulose and fermentable galacto-oligosaccharide, in a rat model of colorectal carcinogenesis: fermentable fibre confers greater protection than non-fermentable fibre in both high and low fat backgrounds. Carcinogenesis 20: 651-656.

32. van Beresteyn EC, van Schaik M, Mogot MF. 1979. Effect of bran and cellulose on lipid metabolism in obese female Zucker rats. J Nutr 109: 2085-2097.

33. de La Serre CB, Ellis CL, Lee J, Hartman AL, Rutledge JC, Raybould HE. 2010. Propensity to high-fat dietinduced obesity in rats is associated with changes in the gut microbiota and gut inflammation. Am J Physiol Gastrointest Liver Physiol 299: G440-G448.

34. Turnbaugh PJ, Ridaura VK, Faith JJ, Rey FE, Knight $\mathrm{R}$, Gordon JI. 2009. The effect of diet on the human gut microbiome: a metagenomic analysis in humanized gnotobiotic mice. Sci Transl Med 1: 6ra14. 